\title{
Artificial Lighting and Its Relation with Body Posture in Office Workplaces
}

\author{
Zahra Pirmoradi ${ }^{1}$, Rostam Golmohammadi*, Javad Faradmal ${ }^{3}$, Majid Motamedzade ${ }^{4}$
}

1. MSc Student of Occupational Hygiene Engineering, Department of Occupational Hygiene Engineering, School of Health, Hamadan University of Medical Sciences, Hamadan, Iran

2. Professor, Department of Occupational Hygiene Engineering, Health Research Center, School of Health, Hamadan University of Medical Sciences, Hamadan, Iran

3. Assistant Professor, Department of Biostatistics, School of Health, Hamadan University of Medical Sciences, Hamadan, Iran

4. Professor, Department of Ergonomics, School of Health, Health Research Center, Hamadan University of Medical Sciences, Hamadan, Iran

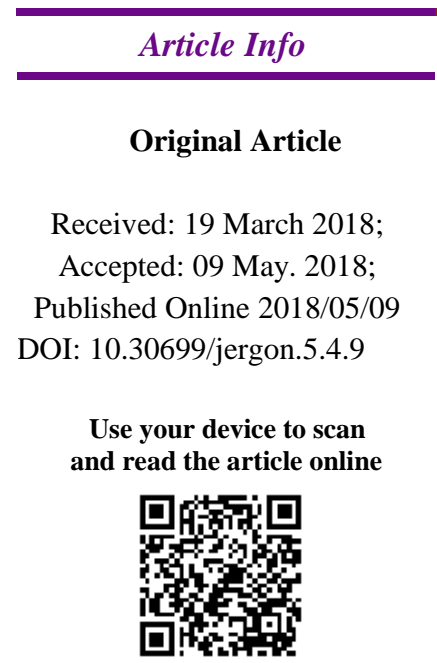

Corresponding Author

Rostam Golmohammadi

Professor, Department of

Occupational Hygiene

Engineering, Health Research

Center, School of Health,

Hamadan University of

Medical Sciences, Hamadan,

Iran

Email:

golmohamadi@umsha.ac.ir.

\section{ABSTRACT}

Background: Inadequate lighting in the workplace can cause unconventional changes in the posture of office workers. Poor ergonomic conditions in the office cause inappropriate postures during work and increase pressure on the musculoskeletal system which can cause some disorders in long-term. In this study, the relationship between work environment lighting with the prevalence and severity of musculoskeletal pain among office workers has been investigated.

Methods: In this study, the intensity of local illumination at work surface and at the perpendicular surface (perpendicular surface to the work surface and at the height of workers eye), and intensity of general lighting was measured based on the standard of The Illuminating Engineering Society (IES) using the SEKONIC, C-7000 SpectroMaster. Also, to assess the prevalence and severity of pain of musculoskeletal disorders, a Nordic Questionnaire and a Body map index were used respectively. To assess the office work strain, Rapid Office Strain Assessment techniques (ROSA) were used. Data were analyzed by SPSS 21.

Results: The results showed that the average intensity of general lighting, local lighting at work surface and at the perpendicular surface were $30.6 \%, 33.9 \%$, and $38.4 \%$ respectively, which is lower than required illumination intensity of Occupational Exposure Limits (OEL). The neck and waist had the highest prevalence of the musculoskeletal disorders among the workers. The highest frequency percentage of scores in the ROSA method was the score $5(41.7 \%)$ which had a significant correlation with illumination intensity.

Conclusion: Illumination intensity can be considered as one of the important factors affecting posture in administrative staff. Therefore, the improvement of illumination intensity can decrease the severity of musculoskeletal pain and improve the body postures of the staff and, consequently, increase their comfort.

Keywords: Artificial Lighting, Musculoskeletal Disorders, Rapid Office Strain Assessment,

Keywords: Artificial Lighting, Musculoskeletal Disorders, Rapid Office Strain Assessment,
Musculoskeletal Pain ics. This is an open-access article distributed under the terms of the Creative Commons Attribution-noncommercial 4.0 Copyright $\odot$ 2018, Journal of Ergonomics. This is and redistribute the material just in noncommercial usages, provided the original work is properly cited
International License which permits copy and

\section{How to Cite This Article:}

Pirmoradi Z, Golmohammadi R, Faradmal J, Motamedzade M. Artificial Lighting and its Relation with Body Posture in Office Workplaces. J Ergon. 2018; 5 (4):9-16 


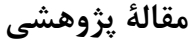 \\ ارتباط روشنايى مصنوعى با وضعيت بدن در كاركنان ادارى}

زهرا يِير مرادى'، رستم كَلمحمدى ץ*، جواد فردمال"، مجيد معتمد زاده طرقبه

اختصاص داده كه هم از ديدكاه سلامت نيروى انسانى و هم از

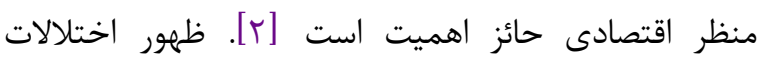
اسكلتى عضلانى مرتبط با كار در دفاتر ادارى در سالهاى اخير

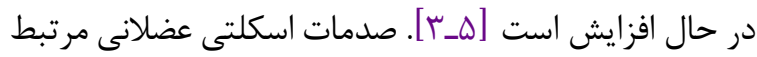

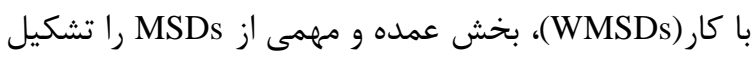

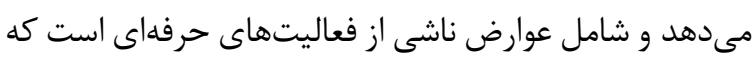
عمدتاً در اثر تكرار كارهاى عضلانى و تحمل فشار عوار هاى مكانيكى و وضعيتهاى بدنى نامناسب و خارج از حدود فيزيولوزيك رخ مى دهد [ع]. خستخى هاى موضعى و ناراحتىها و دردهاى بلى
روشنايى نامناسب در محيط كار، خذشته از تاثير فيزيولوزيك بر سيسته بينايى، ناراحتىهاى جانبى ديگرى از

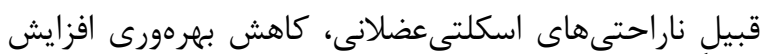
غيبتهاى ناشى از كار و بروز حوادث را نيز سبب ميىشود. انسان براى تعامل مؤثر با محيط كار و تجهيزات همواره نيازمند

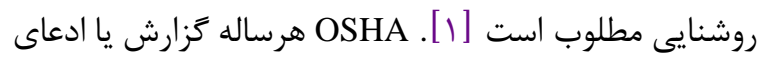
غرامت دو ميليون فرد مبتلا به WMSDs, در امريكا گزارش مى دهد. صدمات اسكلتىعضلانى، بخش عمدهاى از ناراحتى -

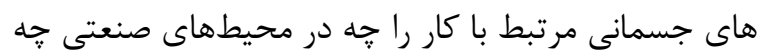
در فعاليتهاى ادارى، آموزشى، خدماتى و ساير موارد به خود 
و دردهاى اسكلتىعضلانى و وضعيتهاى بدن، حين كارِ كاركنان ادارى شهر همدان انجام شد.

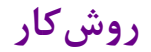

اين مطالعه توصيفى، تحليلى ـ مقطعى است كه بين

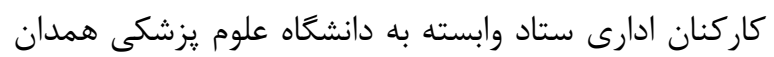
با هدف تعيين اثر روشنايى بر علائم و دردهاى اسكلتى عضلانى

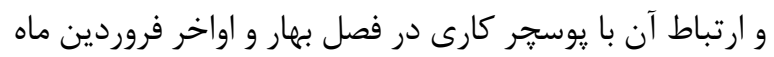
سال 9ها در طول شيفت كارى انجام شد. اندازهكيرى روشنايى در •ه اتاق بلصورت تصادفي ساده انجام شد. در اين

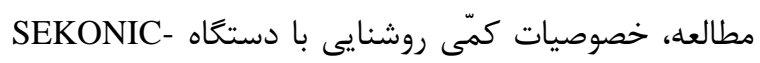

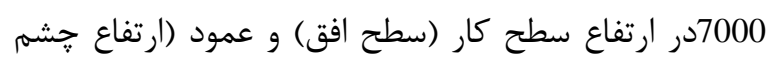

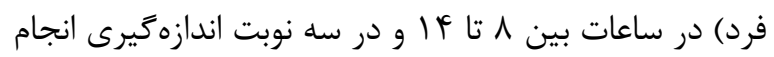

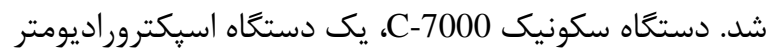

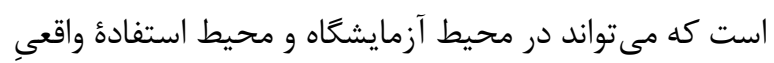

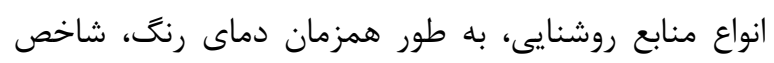

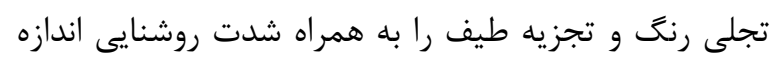

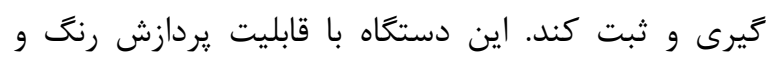

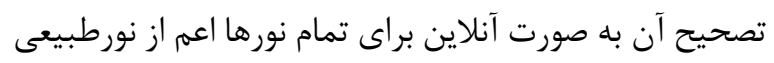

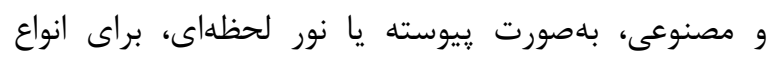

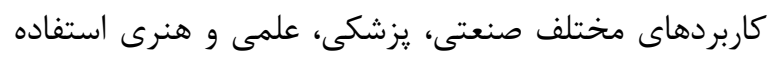

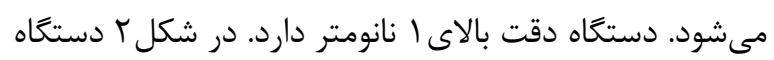

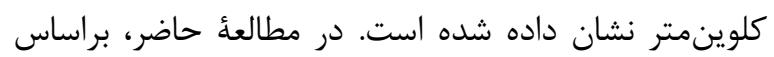

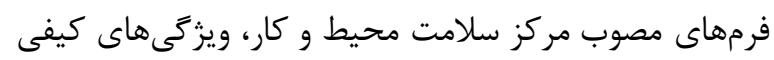

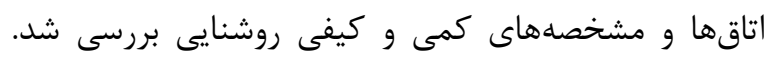

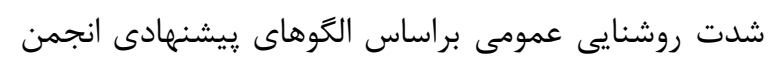

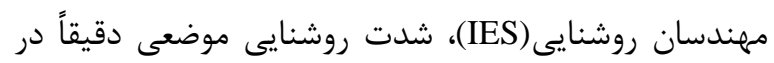

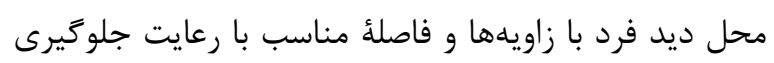

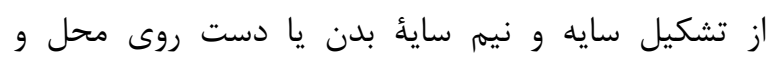

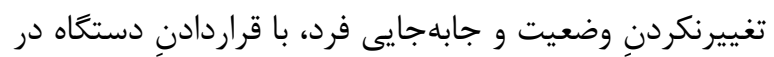

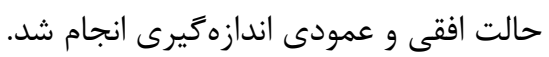

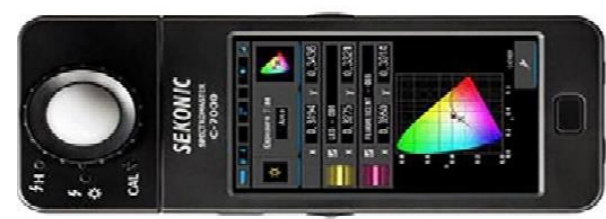

شكل r. دستخاه اسيكترور اديومتر SEKONIC-7000

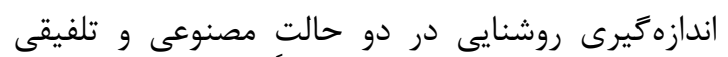

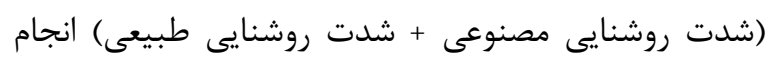

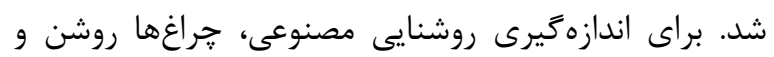

اسكلتى عضلانى باعث شكايت كارمندان از اين ناراحتى ها مى-

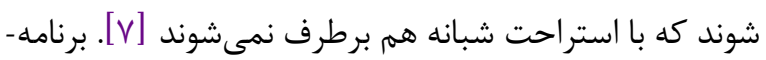

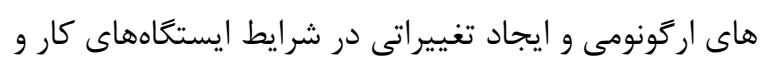

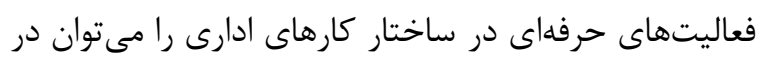

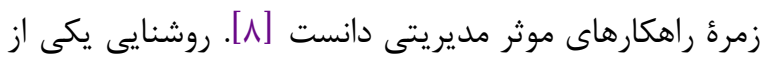

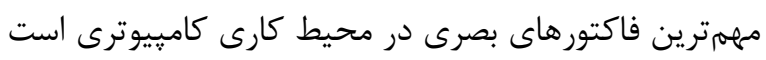

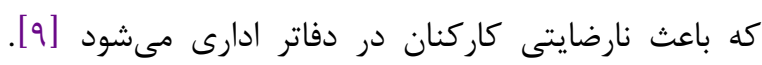

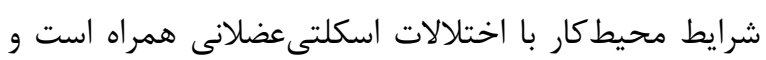

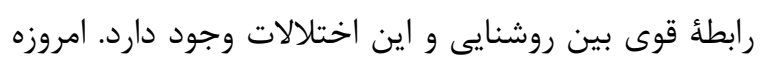

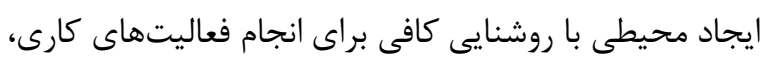

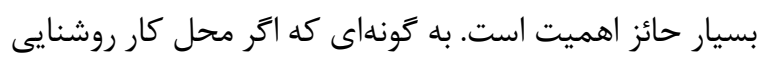

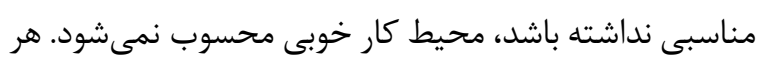

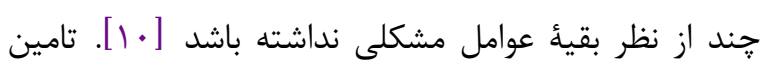

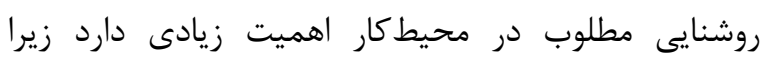

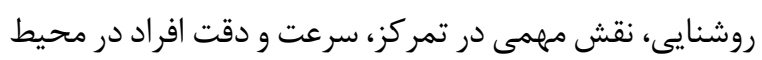

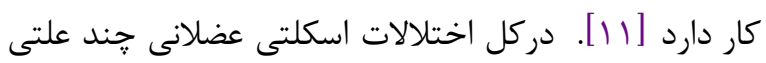

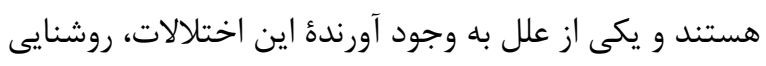

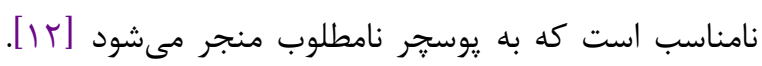

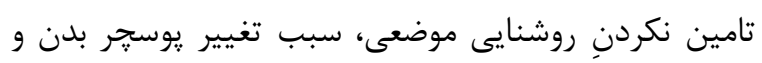

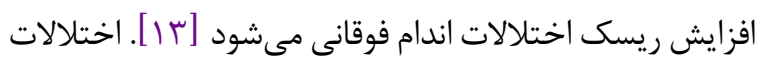

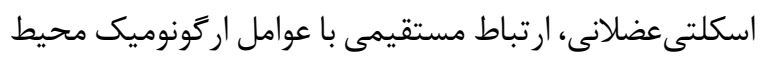

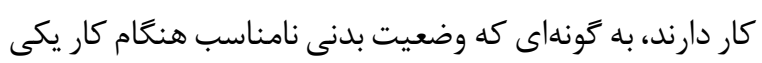

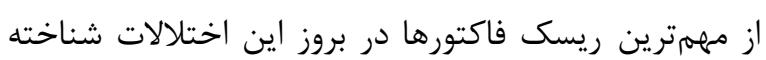

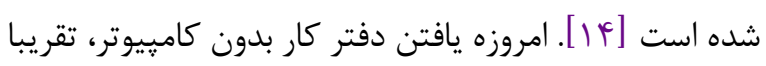
غيرممكن است. مطالعات نشان داده است كه تابش بأش خيره

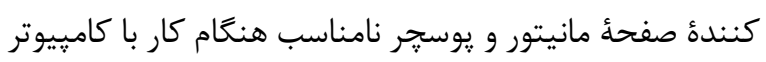

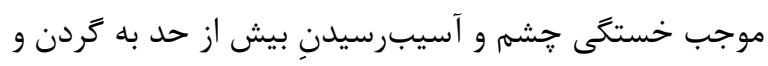

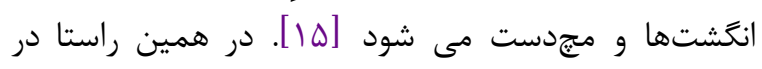

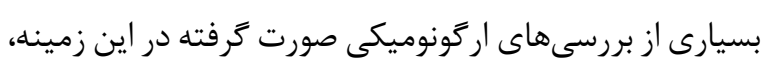

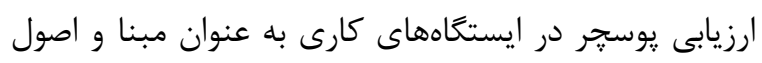

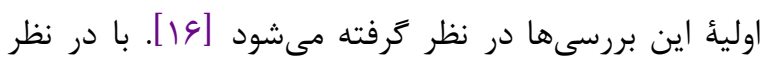
كرفتنِ اينكه تأمين روشنايى كافى و مطلوب حائز ائز اهميت بوده

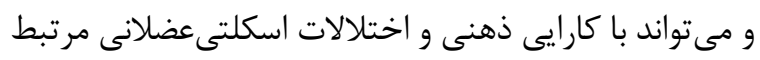

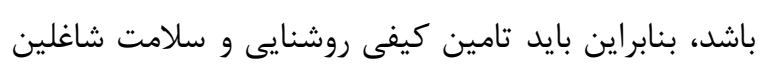

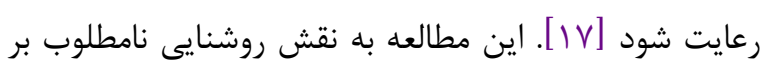

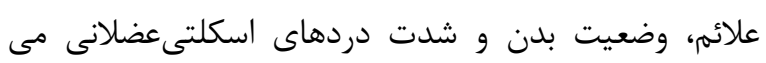

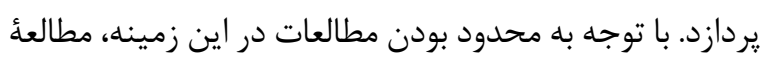

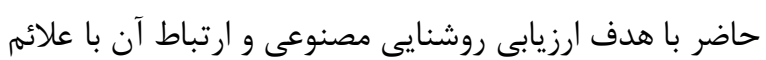


اين روش بين 9-9 (جمع امتيازات قسمتهاىA، B و C

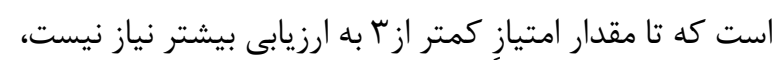

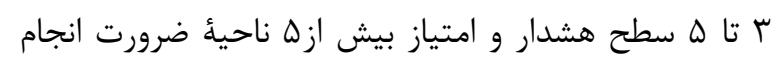

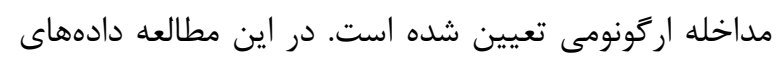

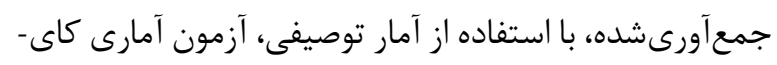

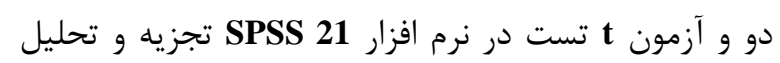

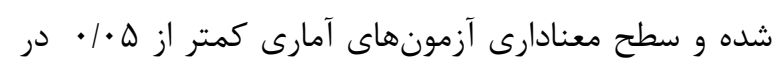
نظر ترفته شد.

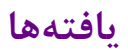

در اين مطالعه ميانگَين سنى افرادمطالعه

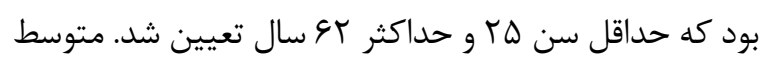

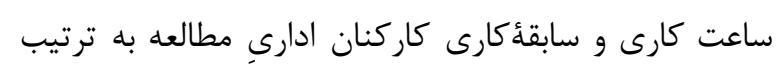

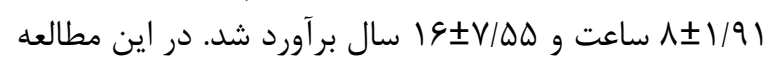

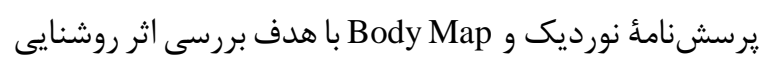

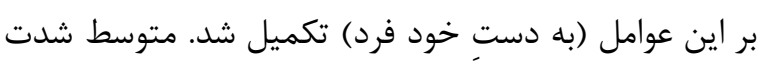
روشنايى عمومى FrV/OVII|

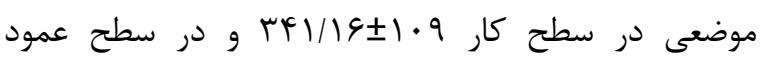

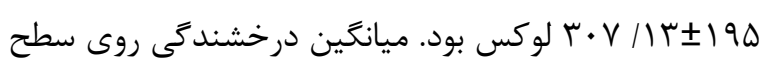
كار متر

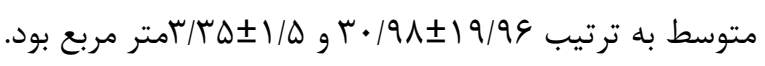

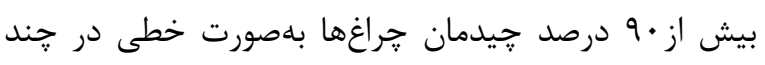

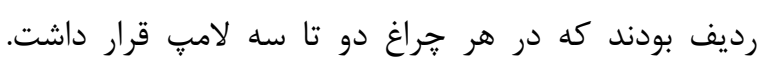

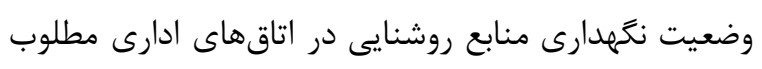

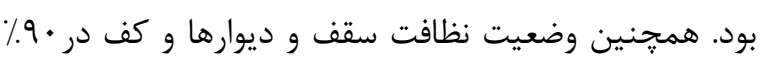

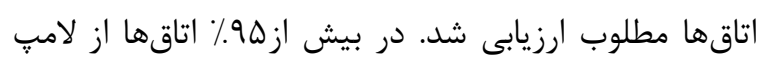

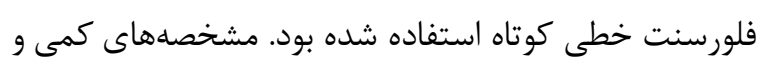

كيفى روشنايى در جدول هاى او ب نشان داده شده است.

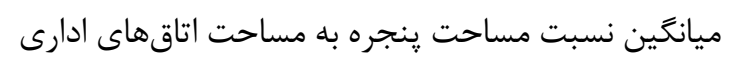

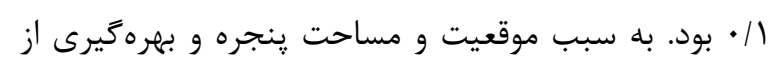

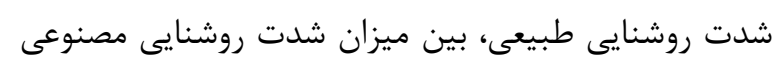
و تلفيقى تفاوت وجود دارد.
يردهها كشيده، براى اندازمخيرى روشنايى تلفيقى، خراغها

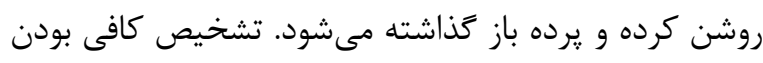

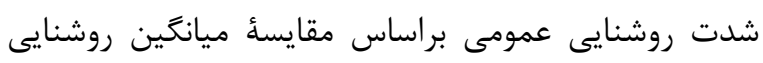

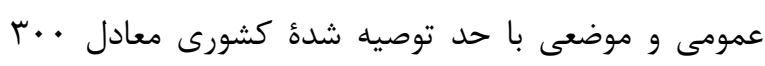

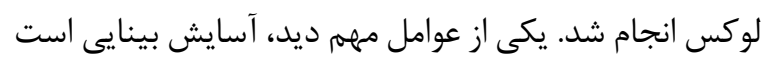

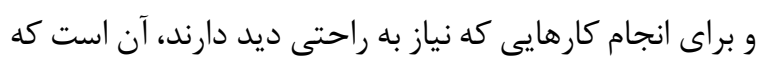

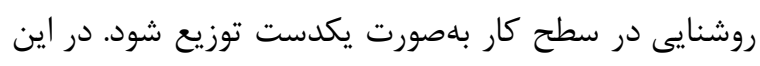
مطالعه به منظور محاسبهُ شاخص يكدستى و مقايسه با مقادير استاندارد، از فاكتور نسبت يكنواختى (من

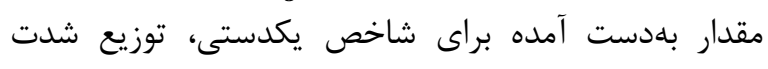

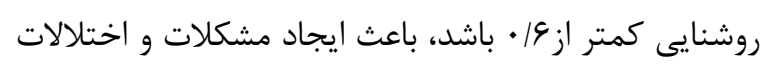

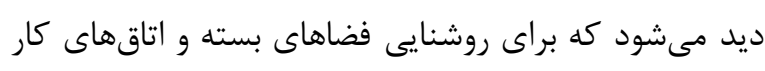

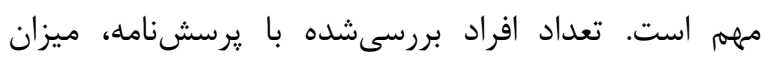

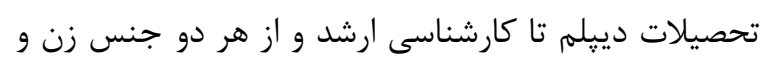

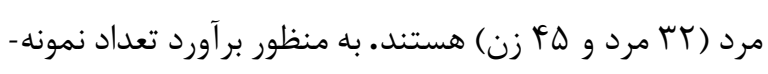

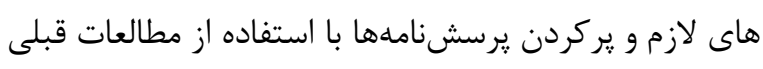

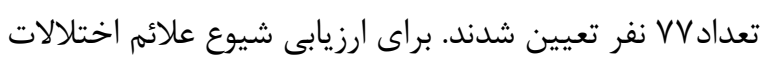

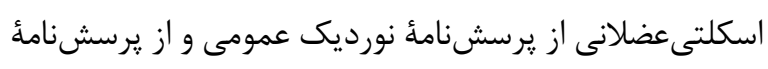
Body Map

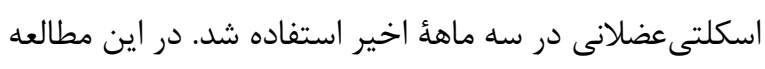

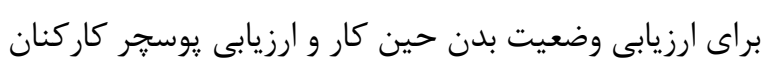

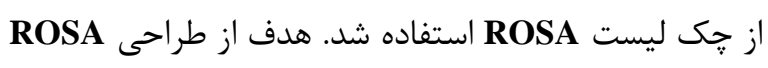

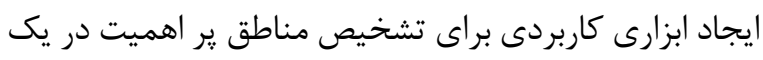

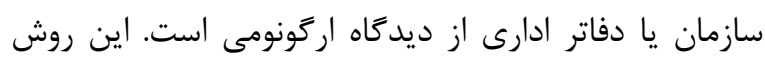

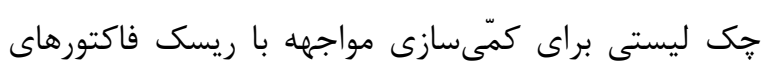

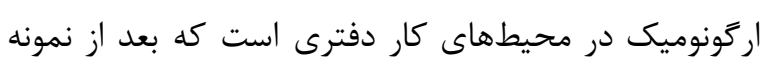

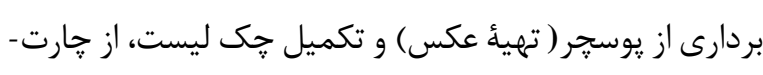

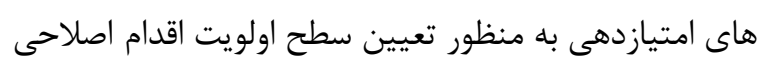

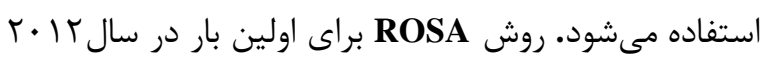

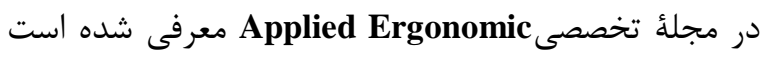

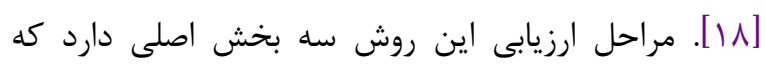

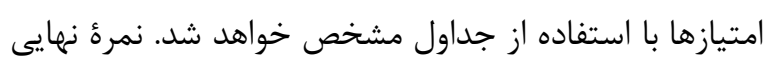


جدول ا. مشخصات كيفى اتاقهاى اداري مطالعه

\begin{tabular}{|c|c|c|}
\hline اتاقهاى ادارى(درصد) & معيار سنجش & متغير \\
\hline$\forall \wedge(१ ९)$ & فلورسنت خطى كوتاه & \multirow{3}{*}{ نوع منبع روشنايى } \\
\hline$r\left(\varphi^{\mathcal{E}}\right)$ & فلورسنت فشرده & \\
\hline$r\left(\varphi^{\mathcal{E}}\right)$ & نقطهاى & \\
\hline$r\left(\varphi^{\mathcal{E}}\right)$ & خطى در يك رديف & \multirow{3}{*}{ جيدمان منابع روشنايى } \\
\hline Fq(9T) & \multirow{2}{*}{ خطى در خند رديف } & \\
\hline $9(1 \vee)$ & & \\
\hline $9($ ( V) & جنوبى & \multirow{3}{*}{ موقعيت هنجره } \\
\hline $\mid 9(\pi \mid)$ & شرقى & \\
\hline rq(19) & 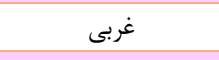 & \\
\hline$F F(\lambda r)$ & مطلوب & \multirow{2}{*}{ وضعيت نظافت ينجره ها } \\
\hline $9(1 V)$ & نامطلوب & \\
\hline
\end{tabular}

\begin{tabular}{|c|c|c|c|c|}
\hline \multirow[t]{2}{*}{ عمومى } & \multicolumn{2}{|c|}{ موضعى } & \multicolumn{2}{|c|}{ روشنايى } \\
\hline & سطح عمود & سطح كار & & \\
\hline 94 & $1 \Delta F$ & $1 \cdots$ & حداقل & \multirow{5}{*}{ 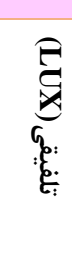 } \\
\hline 111. & $\Delta \Lambda$. & 199. & حداكثر & \\
\hline$r \wedge$. & $1.1 / 9 \mathrm{~V}$ & rqV/AD & انحراف معيار & \\
\hline TTYNG & $F V \cdot / 9 F$ & $999 / 99$ & ميانگين & \\
\hline .119 & $\cdot / F V$ & $\cdot / l f$ & UR' $^{\prime}$ & \\
\hline 91 & 9. & 94 & حداقل & \multirow{5}{*}{$\begin{array}{l}\text { E् } \\
\xi \\
\xi \\
\xi \\
\xi\end{array}$} \\
\hline DYF & $9 \wedge \mathrm{V}$ & . & حداكثر & \\
\hline$\| 19 / 1$ & 190 & 1.9 & انحراف معيار & \\
\hline frV/DV & $r \cdot v / l r$ & TFI/IG & ميانگين & \\
\hline . & .119 & $\cdot \pi$ & UR & \\
\hline
\end{tabular}

لحاظ آمارى بين روشنايى موضعى مصنوعى و :يوسجر،

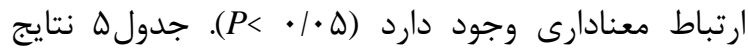
ارتباط روشنايى و سطح نمرات ROSA را نشان مى دهدد.

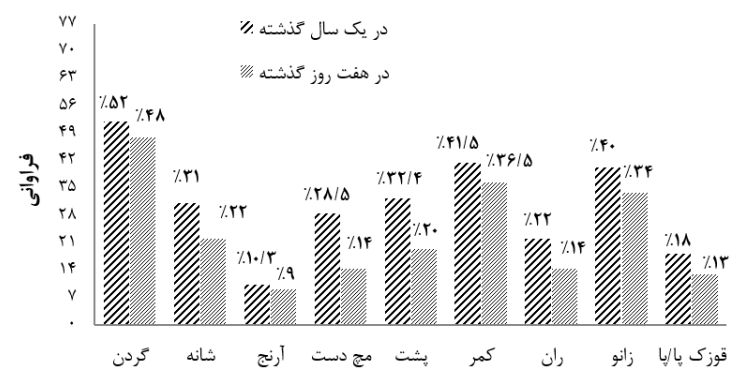

نمودار ا. ميزان شيوع اختلالات اسكلتى عضلانى در كاركنانِ مطالعه
طبق نمودار ا افراد مطالعه در يك سال گذشته بيشترين

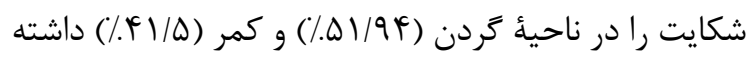

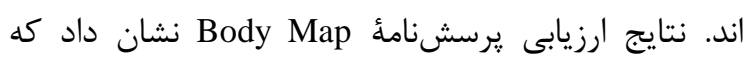

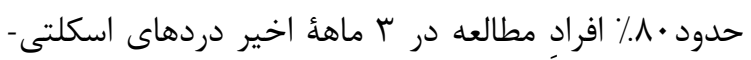

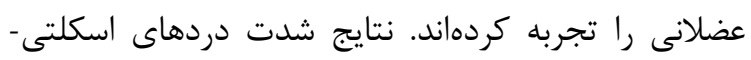
عضلانى تجربه شده افراد در نواحى مختلف بدن در دربه جدول

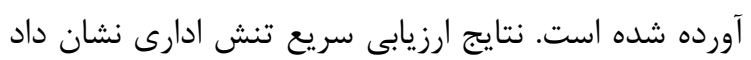

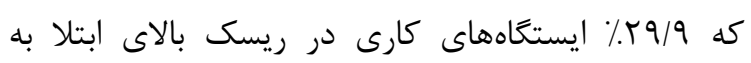

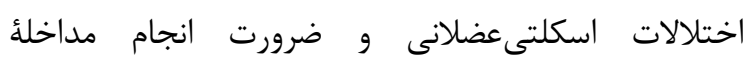
ارگتونوميك (امتياز بيش از ه) قرار دارند. جدولأل نتايج

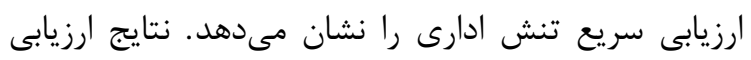

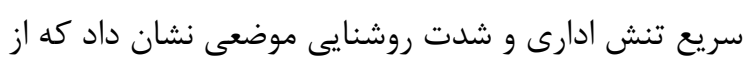

1 .(Uniformity Ratio) UR

2. kelvin 
زهرا يِرمرادى و همكاران | ارتباط روشنايى مصنوعى با وضعيت بدن در كاركنان ادارى

جدول r. فراوانى شدت ناراحتى در نقاط مختلف بدن با استفاده از مقياس نرخَذارى عددى خشمى

\begin{tabular}{|c|c|c|c|c|c|}
\hline $\begin{array}{l}\text { حداكثر (درصد) } \\
\text { حاراحتى) }\end{array}$ & $\begin{array}{l}\text { شديد(درصد) } \\
\text { شاراحتى }\end{array}$ & $\begin{array}{l}\text { متوسط(درصد) } \\
\text { ناراحتى) }\end{array}$ & حداقل ناراحتى & $\begin{array}{l}\text { كم (درصد) } \\
\text { ناراحتى }\end{array}$ & نقاط بدن \\
\hline $\mid r(19 / \Gamma \Delta)$ & $\mid V(Y Y / F \mid)$ & $\mid r(\mid q / \Gamma \Delta)$ & $10(Y F / / 9)$ & $9(9 / \mathrm{V})$ & تردن \\
\hline$f(\varepsilon / f \Delta)$ & $\Delta(\wedge)$ & $1 \wedge(r 9)$ & $1 \wedge(r q)$ & $\mid V(Y Y / F \mid)$ & شانه / بازوى راست \\
\hline . & $f(\varepsilon / f \Delta)$ & $V(11 / r q)$ & $V(11 / r 9)$ & $f f(V \cdot / 98)$ & آرنج/ ساعد دست راست \\
\hline $1(1 / 91)$ & $1(1 / 91)$ & $1 Q(Y F / \mid 9)$ & $V(11 / 79)$ & $M F(\Delta F / A r)$ & مج/ دست راست \\
\hline$f(\xi / f \Delta)$ & $V(11 / r 9)$ & $1 T(Y \cdot / 9)$ & $9(|F / \Delta|)$ & $r \wedge(F Q / \backslash \varphi)$ & زانو/ ران ياى راست \\
\hline$r(T / T r)$ & $\Delta(\wedge)$ & $\Lambda(1 r / 9)$ & $r(\mathcal{F} / \Lambda)$ & $\operatorname{fF}(V \cdot 199)$ & ساق / يا راست \\
\hline$f(\varepsilon / f \Delta)$ & $\Delta(\wedge)$ & $1 \Gamma(T \cdot / 9)$ & $1 \cdot(|9| \mid r)$ & $r \cdot(\lceil\Lambda / r \Lambda)$ & شانه/بازوى حِ \\
\hline$r(\boldsymbol{F} / \Lambda)$ & $r(\boldsymbol{\Psi} / \Lambda)$ & $f(\varepsilon / f \Delta)$ & $V(11 /$ 9$)$ & $F \Delta(V Y / Q)$ & آرنج / ساعد دست جِ \\
\hline$r(T / T r)$ & $\Delta(\Lambda)$ & $9(9 / 7)$ & $1 \cdot(|9| \mid r)$ & $r q(\xi K / 9)$ & مجج/ دست جب \\
\hline $1 \cdot(19 / 1 T)$ & $r r(Y V / \cdot q)$ & $\mid F(Y r / \Delta \Lambda)$ & $\Lambda(1 Y / 9)$ & $V(11 / \Gamma 9)$ & كمر \\
\hline$r(T / T r)$ & $r(\mathcal{F} / \Lambda)$ & $\Delta(\wedge)$ & $9(9 / V)$ & $r q(V F / / 9)$ & باسن \\
\hline$\Delta(\wedge)$ & $\Lambda(1 Y / 9)$ & $9(|F / D|)$ & $9(9 / V)$ & $r \mathcal{H}(\Delta F / \Lambda Y)$ & زانو/ ران پياى جٍ \\
\hline $1(1 / 91)$ & $9 / V(\varphi)$ & $\Delta(\wedge)$ & $f(\xi / f \Delta)$ & $F q(V F / / 9)$ & پا/ ساق ياى جֶ \\
\hline
\end{tabular}

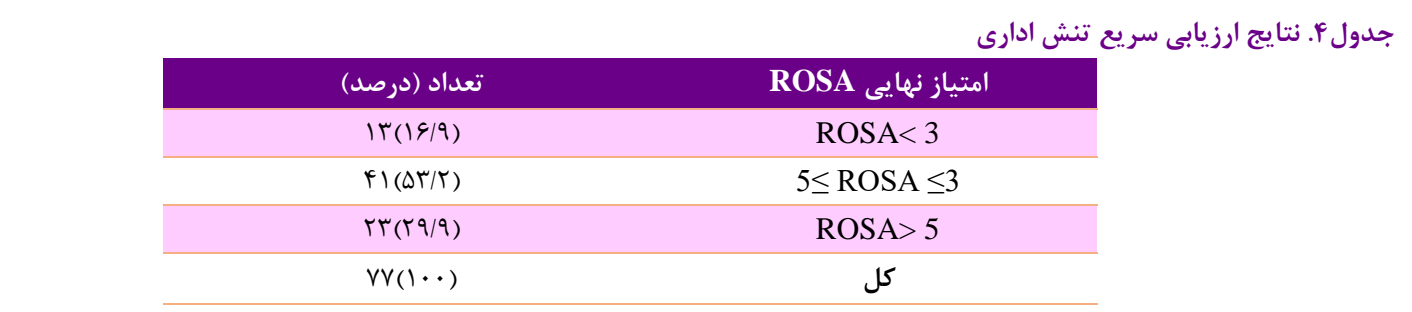

جدولهـ. نتايج ارتباط روشنايى و سطح نمرات ROSA

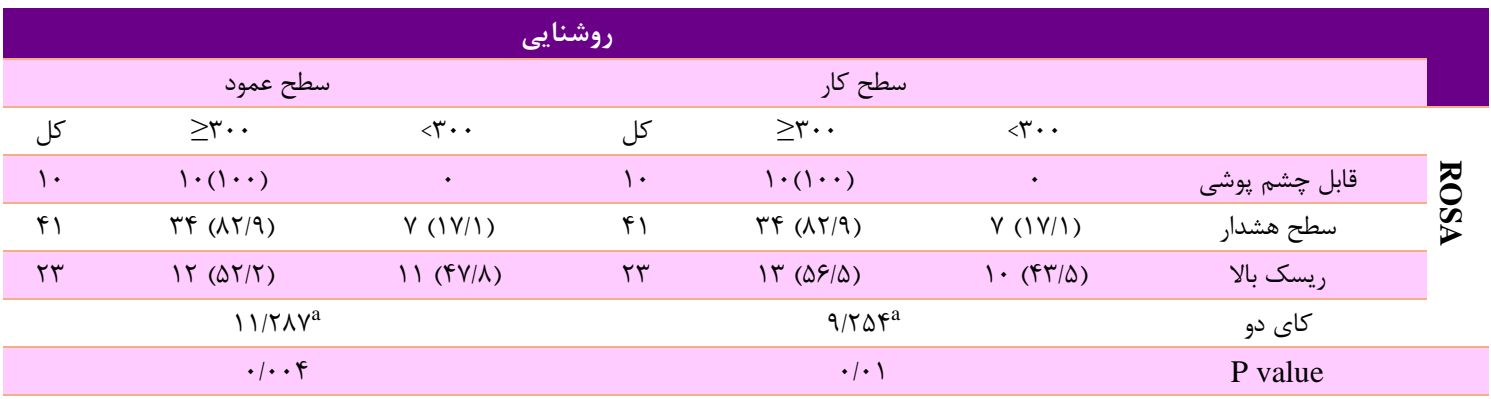

كار با آسايش بصرى و ارگونوميك متناسب نبوده است. نتايج مطالعه مجيدى و همكاران در كتابخانههاى شهر زنجان كه به

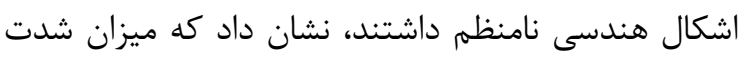

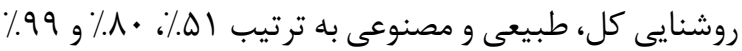

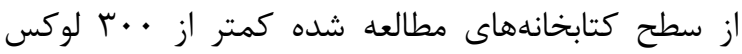

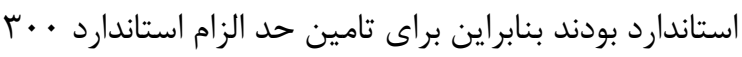

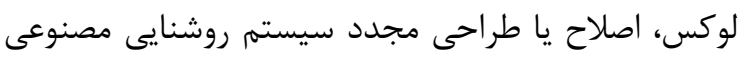

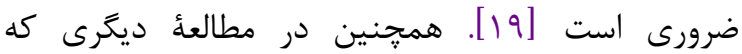
كلمحمدى و همكاران در همين راستا با نتايج مشابه حدود • 9\% انجام دادند، سامانههاى روشنايى عمومى داخلى،

جدول F. نتايج ارزيابى سريع تنش ادارى . 
كامبيوتر در وضعيت بدترى قرار مى گيرد و در نهايت ريسك

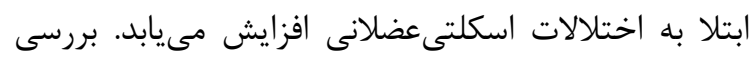

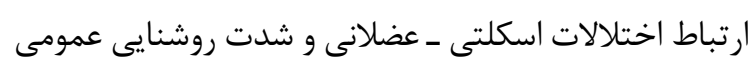

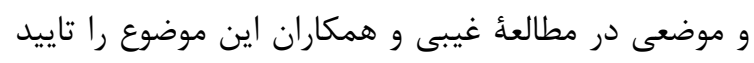

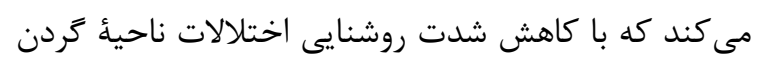

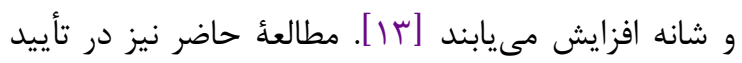

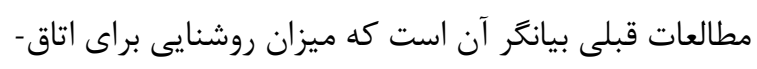

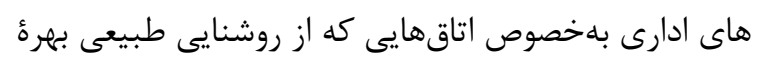

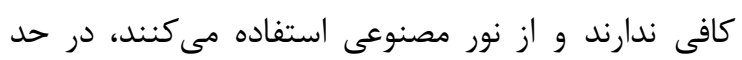

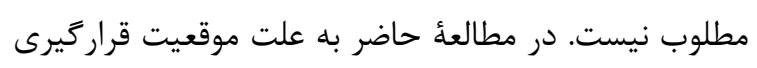

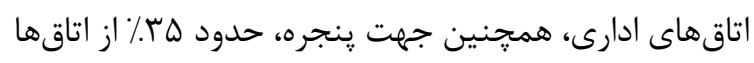

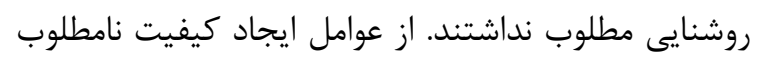

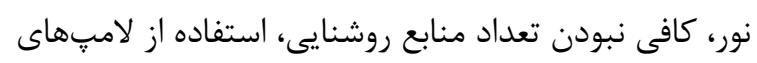

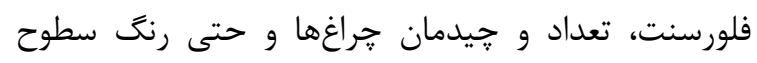

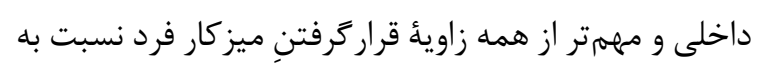

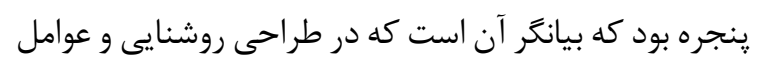
محيطى مربوط به محيط ادارى به كميّت و كيفيت منابع نور

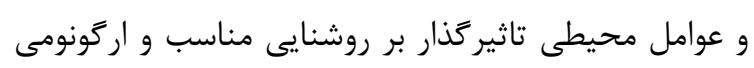
بصرى افراد كمتر توجه شده است.

\section{نتيجه كيرى}

نتايج مطالعهُ حاضر نشان داد كه اغلب اتاقهاى ادارى،

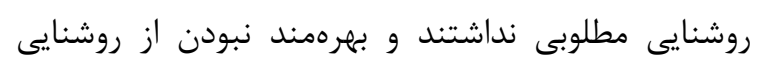

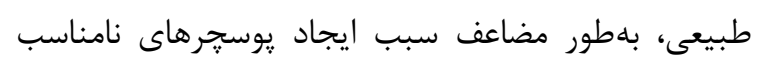
كارى در كاركنان ادارى شده است. اكثر شاغلين در ناحئ

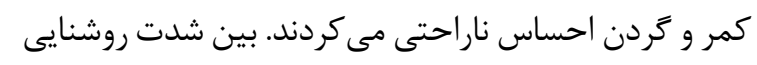

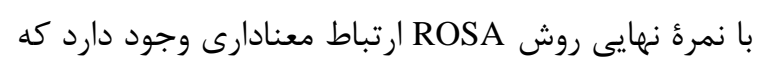

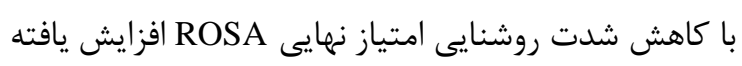

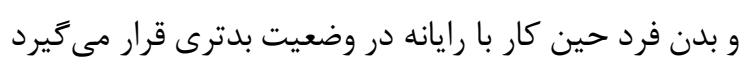

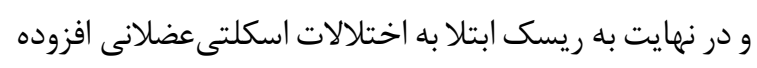

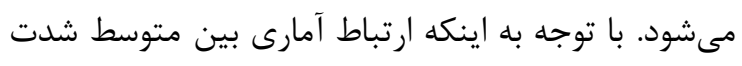

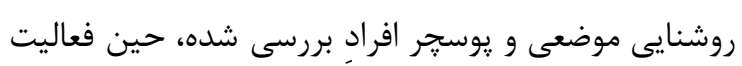

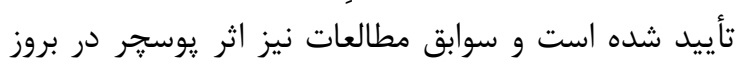

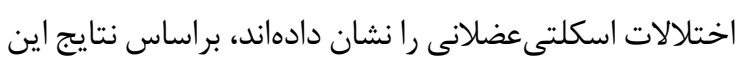

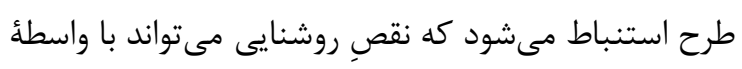
يوسجر كار بر اختلالات اسكلتى عضلانى مؤثر باشد.

\section{تقدير و تشكر}

نويسندًان اين مطالعه از معاونت تحقيقات و فناورى تئري

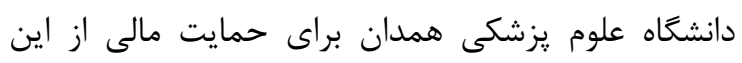

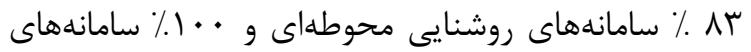

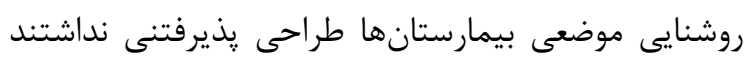

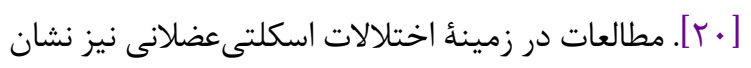

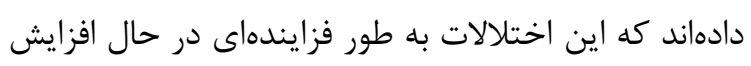

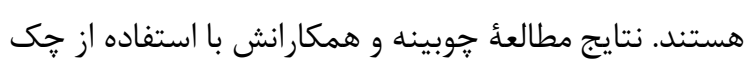

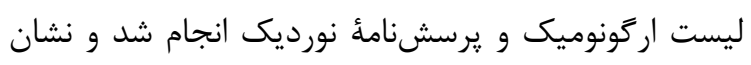
داد كه نواحى كمر و ₹ردن به ترتيب و ميزان شيوع علائم اختلالات اسكلتى عضلانى بين كاردنان

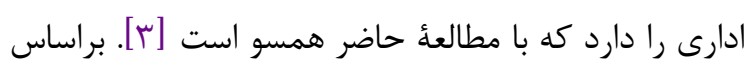
مطالعهُ قنبرىسرتنگ و همكارانش بين كاربران كارئ مامييوتر،

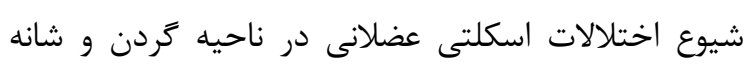

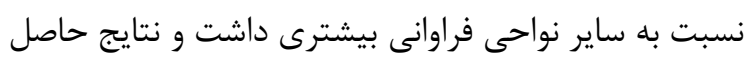

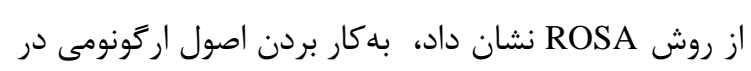

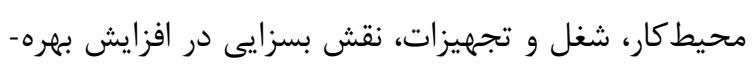

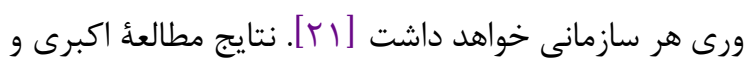

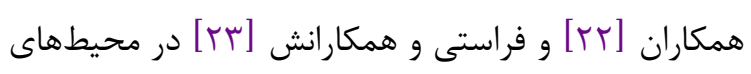

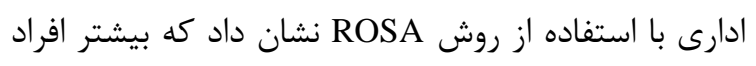

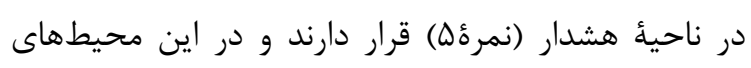

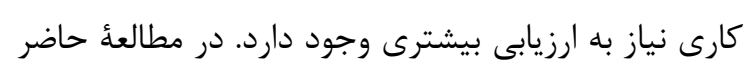

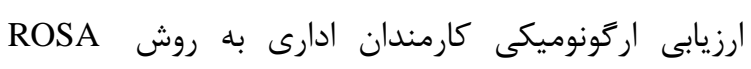

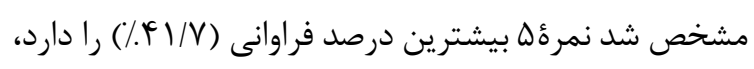

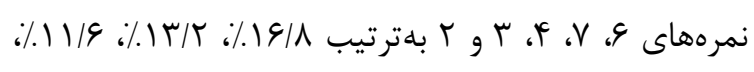

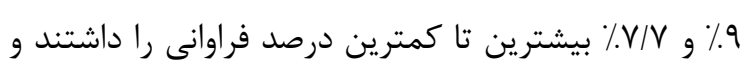

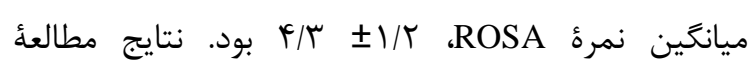

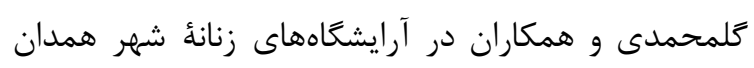

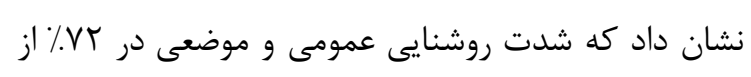

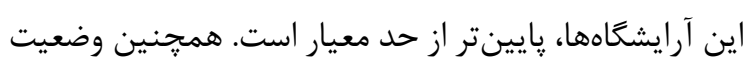

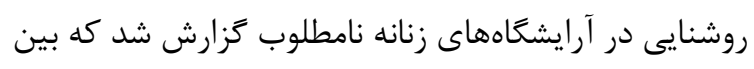
روشنايى عمومى و اختلالات اسكلتى عضلانى آرايشكران

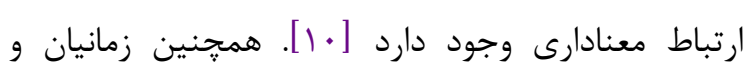

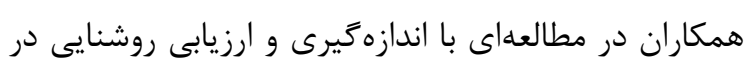

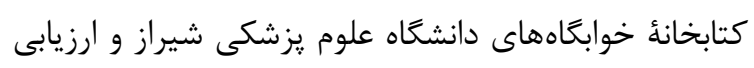

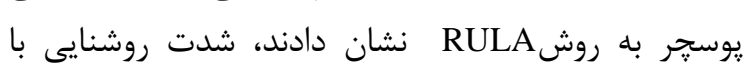

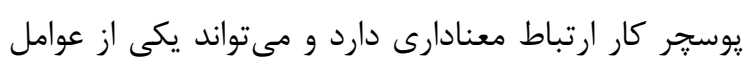

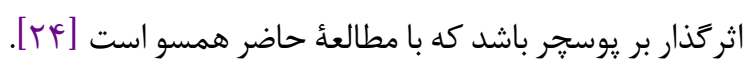

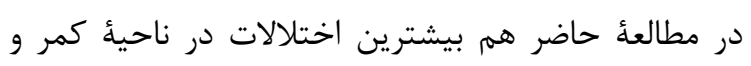

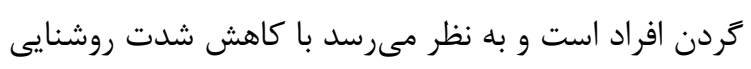

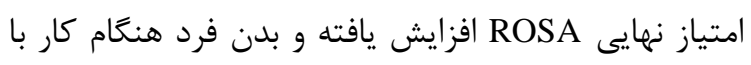




زهرا بيرمرادى و همكاران | ارتباط روشنايى مصنوعى با وضعيت بدن در كاركنان ادارى

$$
\begin{aligned}
& \text { تعارض منافع } \\
& \text { بين نويسند }
\end{aligned}
$$

\section{References}

1. Koohpaye S H, Zakerian S A, Kakooei H. Lighting measurement in Shemiranat health center based on EN 12464-1 European standard. Health and Safety at Work. 2013;3(1):11-8.

2. O'Reilly M, Finder B, Werrell M, The Ergonomics Guide to Computer Workstations. 2nd ed. Illinois: National Safety Council; 2007.

3. Choobineh A, Rahimi Fard H, Jahangiri M, Mahmood Khani S. Musculoskeletal Injuries and Their Associated Risk Factors . Iran Occup Health. 2012;8(4):70-81.

4. Matos M, Arezes PM. ergonomic evaluation of office workplaces with rapid office strain assessment (ROSA). Procedia Manuf. 2015;3:4689-94. https://doi.org/10.1016/j.promfg.2015.07.562

5. Pereira MJ, Straker LM, Comans TA, Johnston V. Inter-rater reliability of an observation-based ergonomics assessment checklist for office workers. Ergonomics. 2016;59(12):1606-12. https://doi.org/10.1080/00140139.2016.1157215 PMID:26910231

6. Van Eerd D, Munhall C, Irvin E, Rempel D, Brewer S, Van Der Beek A, et al. Effectiveness of workplace interventions in the prevention of upper extremity musculoskeletal disorders and symptoms: an update of the evidence. Occup Environ Med. 2016;73(1):6270. https://doi.org/10.1136/oemed-2015-102992 PMID:26552695 PMCID:PMC4717459

7. Poochada W, Chaiklieng S. Ergonomic risk assessment among call center workers. Procedia Manuf. https://doi.org/10.1016/j.promfg.2015.07.543

8. Ritchie CL, Miller LL, Antle DM. A case study detailing key considerations for implementing a telehealth approach to office ergonomics. Work. 2017;57(4):469-73. https://doi.org/10.3233/WOR172579 PMID:28777764

9. Shikdar AA, Al-Kindi MA. Office ergonomics: deficiencies in computer workstation design. Int $\mathrm{J}$ Occup Saf Ergon. 2007;13(2):215-23. https://doi.org/10.1080/10803548.2007.11076722 PMid:17599795

10. Golmohammadi R, Chahardoli Z, Motamedzade M, Farhadian M. Evaluation of Artificial Lighting and its Relationship with Body postures During Work in Hamadan Women's Hairdressers. johe. 2017;4(2):2633.

11. Golmohamadi R, Lighting Engineering. 3nd ed. Hamadan: Daneshjoo; 2014.

12. Nadri H, Nadri A, Khanjani N, Nadri F, Jafari AR. Evaluating the Factors Effective on Musculoskeletal Disorders among the Employees of one of Qazvin's Governmental Offices. J Health Dev. 2013;2(2):1066.

13. Gheibi L, Ranjbarian M, Hatami H, Khodakarim S. The relationship between the prevalence of

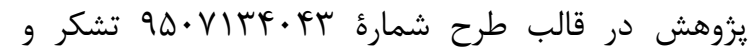

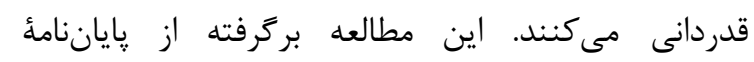

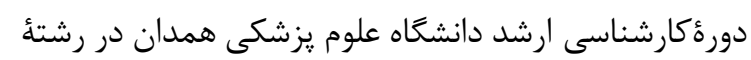

مهندسى بهداشت حرفهاى است.

musculoskeletal disorders in carpet weavers and the lighting in carpet weaving workshops in Takab in 2013. J Ergon. 2015;3(2):35-43.

14. Ghanbary A, Habibi E. Evaluation of Musculoskeletal disorders among computer Isfahan. Iran J Health Environ, 2015;2(3):330-4.

15. Talwar R, Kapoor R, Puri K, Bansal K, Singh S. A study of visual and musculoskeletal health disorders among computer professionals in NCR Delhi. Indian J Community Med. 2009;34(4):326-8. https://doi.org/10.4103/0970-0218.58392 PMID:20165627 PMCID:PMC2822194

16. Habibi E, Ebrahimi H, Barakat S, Maghsoudian L. Ergonomic Assessment of Musculoskeletal Disorders Risk Factors in Office Staff using ROSA Method and Its Relation with Efficiency. J Mil Med. 2017;19(1):31-9.

17. Center H. Education, Occupational exposure limits. 4nd ed. Hamadan: Daneshjoo; 2016.

18. Sonne M, Villalta DL, Andrews DM. Development and evaluation of an office ergonomic risk checklist: ROSA-Rapid office strain assessment. Appl Ergon. 2012;43(1):98-108.

https://doi.org/10.1016/j.apergo.2011.03.008 PMID:21529772

19. Daviran I, Khodaie D, Gholami S, Danesh Dost M. Measurement of visual comfort components in urban landscape (with emphasis on Azam Zanjan Husseinieh neighborhood). Geography and Environment. 2013;1(3):45-60.

20. Golmohamadi R, Shafiee Motlagh M, Jamshidi Rastani M, Salimi N, Valizadeh Z. Assessment of Interior and Area Artificial Lighting in Hospitals of Hamadan City. johe. 2014;1(1):47-56.

21. Ghanbary-Sartang A, Habibi H. Evaluation of musculoskeletal disorders to method Rapid Office Strain Assessment (ROSA) in computers users. J Prev Med. 2015;2(1):47-54

22. Akbari J, Kazemi M, Mazareie A, Moradirad R, Razavi A. The Ergonomic assessment of exposure to risk factors that cause musculoskeletal disorders in Office workers by using ROSA. J Ilam Univ Med Sci. 2017;25(2):8-17. https://doi.org/10.29252/sjimu.25.2.8

23. Ferasati F, Sohrabi M, Jalilian M. Evaluation of WMSDs in VDT users with Rapid office strain assessment (ROSA) method. J Ergon. 2014;1(3):6574.

24. Zamanian Z, Barzideh M, Ghanbari S, Daneshmandi H. The Survey of Noise and Light Effects on Body Posture During the Study in Male Dormitory of Shiraz University of Medical Sciences. Tolooebehdasht. 2014;13(4):48-56. 